\title{
Construction of Human Resource Management Information System of Large Corporations
}

\author{
Yixuan Zhao ${ }^{1, \text { a }}$, Jian $\mathrm{Xu}^{2, \mathrm{~b}}$ * \\ ${ }^{1}$ International School, Beijing University of Posts and Telecommunications, Beijing, China \\ ${ }^{2}$ Department of Economics and Management, Dankook University, Yongin-si, Gyeonggi-do, South Korea \\ a975485914@qq.com, bujiansword@163.com \\ ${ }^{*}$ Corresponding author
}

Keywords: human resource management information system; informalization; large corporation

\begin{abstract}
Human Resource Management (HRM) is very important to the realization of strategic goal, and it has attracted the concern of decision-maker. The paper gives a comprehensive introduction on the construction of Human Resource Management Information System (HRMIS) of large corporations, including the overall planning, requirement analysis, construction implementation and system application. Some methods and suggestions are also put forward to improve the human resource management.
\end{abstract}

\section{Introduction}

Human resource management (HRM) is the core process of business management for large corporations. Management information system can enable large corporations to achieve the human resource management. The essence of informalization is to improve and optimize management processes [1]. With the implementation of human resource management information system (HRMIS), management may shift the focus of large corporation towards optimizing human resources and making strategic decisions, aiming to promote the sustainable development of large corporation in the long run.

Large corporations tend to implement HRMIS at the firm level. Based on the overall strategic planning and the design of HRMIS, three steps are needed to implement human resource management information system.

The first step is to achieve the standardization of basic model of HRMIS. Basic model includes human capital management, organizational structure, employee information, payroll management, and social security management, etc.

The second step is to establish the systematic mechanism for talent development. To achieve the people-oriented goal, operational capability should be reasonably matched with quality requirement. Through the effective and efficient recruitment, training and performance evaluation, talent management should be engaged in every process of HRMIS, which in turn promotes the common development of corporations and employees.

The third step is to build the platform for human resource statistics and analysis. To achieve the real-time analysis, HRMIS should master the human resource status completely and accurately, and provide supports for human resource optimization and strategic decision making.

\section{Plan Making}

The information construction of corporations is quite complicated, which are likely to be postponed. Under the guidance of the construction plan, the plan should be carried out in phases. In each phase, four or five subsidiaries should be chosen as experimental units. The completion of the current plan should follow the start of next plan. The plan with high flexibility should take the resources, workload and required time into full 
consideration. To shorten the construction period, the working plan in the second phase should be carried out at the end of the plan in the first phase.

\section{Requirement Analysis}

The requirement analysis should be made by the professional consulting companies. The ultimate goal of requirement analysis is to determine the system's functional requirements and system performance requirements through the analysis of the business processes related to the management requirements.

Functional Requirements. Functional requirements are mainly related to the specific business management of human resources, including the management of organizational position, personnel information, cadre, payroll and social security, and information statistics and inquiry etc. Besides, for different service objects (e.g., employees, staff in HR department, department heads and leaders), the system should achieve different application requirements.

System Performance Requirements. System performance requirements mainly refer to the performance requirements of the operation of the system itself. The requirements include ease of use, reliability, friendliness and security, and extendibility. HRMIS should process data in a stable and efficient way and ensure the integrity and accuracy of data [2]. The process of corporation's human resource information needs a large amount of data query. Especially, in terms of salary calculation, the relationship database and related modules should be logically designed.

\section{Application System Selection}

The application system selection should take account of domestic and foreign products. Compared with domestic application system, foreign application system is relatively mature with powerful strength, market promotion and a combination of system design and HRM theory. Foreign application system is applicable to various industries.

Due to the characteristics of Chinese enterprises and different management culture, value orientation and moral values between China and the West, it may lead to the great differences in the evaluation of capability structure and cadre management, and the analysis of professional ethics and management capabilities. In recent years, Chinese government has begun to attach importance to the design and development of software system and made great efforts in improving the market competitiveness of domestic application system [3]. In terms of product price, implementation cost and software upgrade, the cost performance of domestic software is lower than that of foreign software.

In the specific selection of application system, the software suppliers should make the matching degree analysis to test the functions of the software, which could enable the corporation to make the right decision.

\section{Implementation Process}

\section{Blueprint Design.}

System design. The mode of centralized deployment and multi-level application should be applied, that is, at the group level the corporation makes the unified design and construction, each subsidiary applies for this design, the server is deployed in the group headquarters, and each subsidiary can have access to the system through LAN or VPN [4]. This is a typical model of group control.

Due to the various types of large corporation's subsidiaries, the subsidiaries should focus their attention on the human resource management system in the process of business operation. Based on the centralized information management, large corporations should make full use of the advantages of business collaboration among the organizations and of decision intelligence among the headquarters. 
Taking into account the development needs of HRM, system application platform tends to be expanded and maintained with the structured design. The whole system is divided into IT infrastructure layer, data layer, business layer and portal layer with information security system, operation and maintenance management system and standards and specifications system.

Business function design. The division of business function depends on system functional orientation and the convenience of the system [5]. This module mainly include organizational management, position management, personnel information management, contract management, attendance management, payroll and social security management, performance management, recruitment management, training management and career management. Fig. 1 illustrates the frame diagram of HRMIS business function.

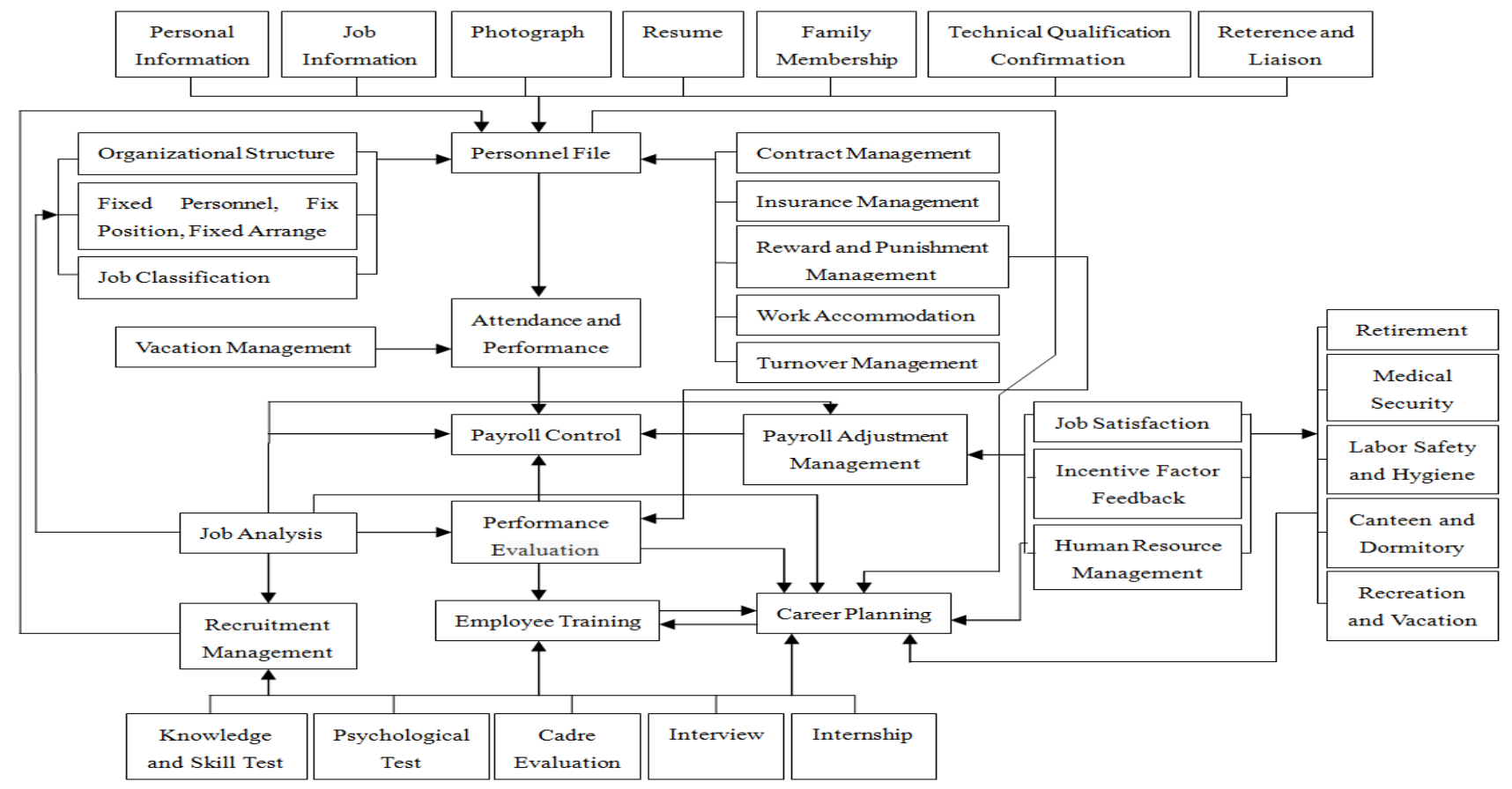

Figure 1. The frame diagram of HRMIS business function

Hardware deployment design. The current application server management needs to use the virtual server. The distribution of WAS server and WEB server depends on the load. The database server, separately deployed, is recommended to use the high-end storage server which is shared with other application system.

Fig. 2 shows the schematic diagram of HRMIS layout.

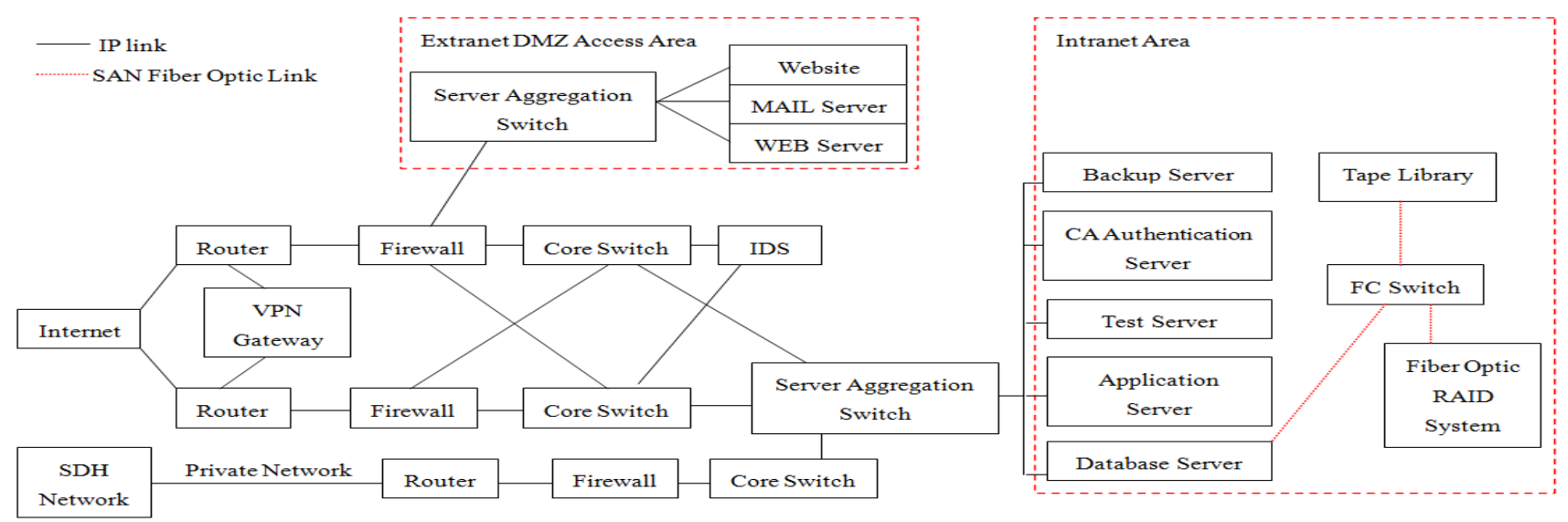

Figure 2. The schematic diagram of HRMIS layout 
Construction Implementation. The system construction must be carried out in the scope of blueprint design. Combined the previous plan with the blueprint, more detailed plan (e.g. monthly plan and weekly plan) should be made. For the requirement change, corporations need overall planning by using the project change management to prevent the occurrence of repetitive tasks [6].

The representative HR professionals should participate in the whole construction of HRMIS, taking the role of key users. The number of participants and participation enthusiasm play a vital role in the successful implementation of HRMIS.

Large corporations should pay much attention to risk control in the implementation of HRMIS. Besides, large corporations need to make risk management plan, carry out risk identification and risk monitoring using qualitative and quantitative analysis. Effective risk management will reduce the likelihood of an occurrence of potential issue [7].

In the whole construction, each type of documents should be kept and managed. Each meeting and each job is required to back up. It is the important materials that provide supports for the successful operation of HRMIS.

System Testing. In the last phase of the system, system testing needs to be carried out. System testing is generally divided into functional testing and performance testing.

Functional testing examines whether all function points of the business module meet the requirements of business applications. The design of test case is a very important part of functional testing. The high-quality test case could effectively test each function point and its association relationship.

Performance testing is used to ensure system stability processing large amounts of information. Performance testing generally needs to be completed with an aid of third-party tools.

\section{System Application.}

Data preparation. Before the operation of HRMIS, the data related to HRM needs to be put into the system. Data preparation is done by the staff of HR department. To ensure the accuracy of data, the data analysis software should be used to perform data verification.

Application training. The training content mainly relates to the application of the system. It will take three to five working days to carry out the comprehensive and systematic training. The training instructors are best acted by key users, and the training materials are compiled on the basis of real practices. After the application training, the system could be applied formally.

\section{Operation and Maintenance Support}

After the operation of HRMIS, the full-time maintenance personnel are required to analyze the system application and repair the system defects. During the transition period from the original construction to the operation, large corporation should focus on the training of maintenance personnel, the construction of operation system and the process construction of management system based on ITIL, including equipment operation and maintenance, business operation and development operation and maintenance. The operation and maintenance system is the basic guarantee for the stable, efficient and continuous operation of HRMIS.

\section{Application Evaluation}

After the application of HRMIS, it is necessary to carry out systematic application evaluation. At the business application and organizational level, the practical application of each subsidiary and each business module should be evaluated. The ultimate goal of application evaluation is to optimize HRMIS.

\section{Conclusions}

The construction of HRMIS in large corporations is a tough task that covers a wide range and constant optimization with the adjustment of human resources. To meet the goal of group control, HRMIS 
needs to take the unified management and business coordination into consideration. The most important task is to establish the management standards and specifications. The business plan should be achieved through the system to match operation control with information application and achieve the value of HRMIS.

\section{Acknowledgement}

We would like to show my deepest gratitude to the anonymous reviewer and the editor of this review. Responsibility for the opinions and remaining errors is ours.

\section{References}

[1] K. Schwalbe, Information Technology Project Management, sixth ed., Engineering Industry, Beijing, 2011.

[2] J.T. Marchewka, Information Technology Project Management, second ed., Electronic Industry, Beijing, 2007.

[3] $\mathrm{K} . \mathrm{Xu}$, Analysis on the structure of human resource management information system in Enterprises, Modern Business Trade Industry, 22 (2010) 145.

[4] Y. Wang, M. Li, Thoughts on Building Human Resource Shared Service Center, China Management Informationization, 9 (2014) 46-48.

[5] L.T. Dai, Design and Development of Human Resource Management Software, China Labor, 54 (2004) 40-48.

[6] J.Z. Liu, The construction of human resource information system of enterprise group, Management Observer, 26 (2007) 44-46.

[7] X.H. Xue, Study on Application of Enterprise Human Resource Management Information System, Economic Review, 21 (2005) 93-95. 